\section{OPEN ACCESS}

Edited by:

Jorge Blanco,

University of Santiago

de Compostela, Spain

Reviewed by:

Juan Marzoa,

University of Santiago

de Compostela, Spain Jesús Santos,

Universidad de León, Spain

${ }^{*}$ Correspondence:

Isabel Otal

otali@unizar.es

María J. García

mariaj.garcia@uam.es

Specialty section: This article was submitted to

Infectious Diseases,

a section of the journal

Frontiers in Microbiology

Received: 28 October 2016

Accepted: 15 February 2017

Published: 06 March 2017

Citation:

Otal I, Pérez-Herrán E Garcia-Morales L, Menéndez MC, Gonzalez-y-Merchand JA, Martín C and García MJ (2017) Detection of a

Putative TetR-Like Gene Related to Mycobacterium bovis BCG Growth

in Cholesterol Using

a gfp-Transposon Mutagenesis

System. Front. Microbiol. 8:315

doi: 10.3389/fmicb.2017.00315

\title{
Detection of a Putative TetR-Like Gene Related to Mycobacterium bovis BCG Growth in Cholesterol Using a gfp-Transposon Mutagenesis System
}

\begin{abstract}
Isabel Otal1,2,3*, Esther Pérez-Herrán ${ }^{1,4}$, Lazaro Garcia-Morales ${ }^{5}$, María C. Menéndez ${ }^{6}$, Jorge A. Gonzalez-y-Merchand ${ }^{5}$, Carlos Martín ${ }^{1,2,3}$ and María J. García ${ }^{6 *}$
\end{abstract}

' Grupo de Genética de Micobacterias, Departamento de Microbiologia, Medicina Preventiva y Salud Pública, Universidad de Zaragoza, Zaragoza, Spain, ${ }^{2}$ Centros de Investigación Biomédica en Red Enfermedades Respiratorias, Instituto de Salud Carlos III, Madrid, Spain, ${ }^{3}$ Instituto de Investigación Sanitaria Aragón, Zaragoza, Spain, ${ }^{4}$ Diseases of the Developing World, GlaxoSmithKline, Tres Cantos, Spain, ${ }^{5}$ Departamento de Microbiología, Escuela Nacional de Ciencias Biológicas, Instituto Politécnico Nacional, Ciudad de Mexico, Mexico, ${ }^{6}$ Departamento de Medicina Preventiva, Universidad Autónoma, Madrid, Spain

In vitro transposition is a powerful genetic tool for identifying mycobacterial virulence genes and studying virulence factors in relation to the host. Transposon shuttle mutagenesis is a method for constructing stable insertions in the genome of different microorganisms including mycobacteria. Using an IS1096 derivative, we have constructed the Tngfp, a transposon containing a promoterless green fluorescent protein ( $g f p$ ) gene. This transposon was able to transpose randomly in Mycobacterium bovis BCG. Bacteria with a single copy of the gfp gene per chromosome from an $M$. bovis BCG::Tngfp library were analyzed and cells exhibiting high levels of fluorescence were detected by flow cytometry. Application of this approach allowed for the selection of a mutant, BCG_2177c::Tngfp (BCG-Tn), on the basis of high level of long-standing fluorescence at stationary phase. This BCG-Tn mutant showed some particular phenotypic features compared to the wild type strain, mainly during stationary phase, when cholesterol was used as a sole carbon source, thus supporting the relationships of the targeted gene with the regulation of cholesterol metabolism in this bacteria. This approach showed that Tngfp is a potentially useful tool for studying the involvement of the targeted loci in metabolic pathways of mycobacteria.

Keywords: transposon mutagenesis, gfp, Mycobacterium bovis BCG, cholesterol, BCG_2177c gene, TetR-family

\section{INTRODUCTION}

Tuberculosis (TB) remains a leading cause of morbidity and mortality among communicable diseases, and it is currently ranked the major killer among worldwide infectious diseases caused by a single pathogen ${ }^{1}$. The HIV/AIDS pandemic, the deterioration of public health systems in developing countries and the emergence of multi (MDR), extensively (XDR), and totally (TDR)

\footnotetext{
${ }^{1}$ http://www.who.org
} 
drug-resistance strains have further contributed to the spread of the pathogen and reinforced the urgent need for more efficient vaccines and treatment against TB (Gunther, 2014). Moreover, latently infected people represent a dangerous reservoir of TB (Garcia and Lopez, 2016). The human population is estimated at approximately 7 billion by the United Nations, with over one third being infected with the tubercle bacilli. Therefore, it can be assumed that more than 2 billion people have latent TB infection (LTBI). Based on this statistics it is not unusual that understanding and controlling LTBI were considered as core parts of the End TB Strategy, launched from 2016 to 2035 by WHO (Garcia and Lopez, 2016).

Cholesterol has been identified as an essential carbon source for LTBI in which the bacteria exist in a non-replicative state termed dormancy (Nesbitt et al., 2010). Several studies have demonstrated that Mycobacterium tuberculosis mutants lacking the capacity to acquire or degrade cholesterol are defective for growth in some animal models of TB (Pandey and Sassetti, 2008; Chang et al., 2009; Nesbitt et al., 2010). Furthermore it has been shown that the metabolism of host-derived carbon sources such as fatty acids and/or cholesterol is crucial for M. tuberculosis persistence in macrophages during chronic infections (Schnappinger et al., 2003; Rengarajan et al., 2005; Pandey and Sassetti, 2008; Miner et al., 2009; Griffin et al., 2012; Rohde et al., 2012).

The M. tuberculosis complex (MTBC) is characterized by 99,95\% sequence similarity at the nucleotide level and a strictly clonal population structure (Brosch et al., 2002). Continuous advances in developing biological tools and reagents have facilitated genetic manipulation of the MTBC (Bardarov et al., 1997; Pelicic et al., 1997). These advances, in combination with the availability of whole genome sequences of multiple strains of members of the MTBC $^{2}$ have allowed for the study of the contribution of individual genes to the M. tuberculosis pathogenicity, including those related to dormancy, the status of the bacilli during LTBI (Forrellad et al., 2013). One of the in vitro conditions required to mimic the dormant state is the stationary phase of growth in the presence of a lipid environment (Rodriguez et al., 2014).

Transposon mutagenesis is a classical procedure to study gene-function of bacteria under a global perspective (Lin et al., 2014; Kwon et al., 2016). In addition, genetic fusions have provided an important means of analyzing basic biological systems from the earliest times of molecular genetics. The basic principle of the genetic fusion approach was to put an assayable gene product under the control of another gene or promoter of interest (named reporter) thus supplying a means to monitor its expression. In this work, we have studied the potential mutagenicity supplied by a transposon that includes a promoterless $g f p$ gene ("green $f$ luorescent protein") as a reporter gene.

The GFP from the jellyfish Aequorea victoria has been extensively used as a useful marker in studies of various biological processes (Cubitt et al., 1995; Valdivia and Falkow, 1998). GFP is a 238-amino-acid-long protein encoded by the $g f p$ gene (Prasher et al., 1992). When excited by blue light at

${ }^{2} \mathrm{ftp}: / / \mathrm{ftp}$. ncbi.nlm.nih.gov a wavelength of $395 \mathrm{~nm}$, the protein emits green light that can be observed in vivo since no substrates or cofactors are needed for the unique post-translational modification that generates the fluorescent chromophore (Cody et al., 1993). GFP has been successfully expressed in a wide range of organisms such as the nematode Caenorhabditis elegans (Chalfie et al., 1994), the small fly Drosophila (Wang and Hazelrigg, 1994; Bach et al., 2007), and pathogenic mycobacteria (Dokladda et al., 2015). Modified transposons containing truncated reporter genes could be useful to identify promoters and study gene expression in mycobacteria. The transposons Tn5367 and Tn5368 contain IS1096 (Cirillo et al., 1991) and both showed to be active in $M$. bovis BCG generating random insertions and giving rise to a set of auxotrophic mutants (Mcadam et al., 1995). These transposons have also been active in several strains of M. tuberculosis (Bardarov et al., 1997; Pelicic et al., 1997).

In the present work, we describe the construction of an IS1096-derivative transposon harboring the reporter $g f p$ gene and its delivering system using a thermo/sucrose sensitive mycobacterial plasmid. This transposon was checked and analyzed in the slow-growing non-pathogen $M$. bovis BCG, belonging to MTBC, which can be manipulated and results can be extrapolated to $M$. tuberculosis. Using flow cytometry, we were able to differentiate populations of fluorescent mycobacteria. Applying this procedure, we isolated the M. bovis BCG_2177c::Tngfp (BCG-Tn) a mutant with high fluorescence at stationary growth phase. The targeted gene, BCG_2177c, a homologous of Rv2160A of $M$. tuberculosis, has been previously identified as a putative member of the TetR-family of transcriptional regulators (Balhana et al., 2015) and members of this family have been associated with the regulation of genes involved in cholesterol metabolism (Casabon et al., 2013; Wipperman et al., 2014). Furthermore, phenotypic and genotypic characterization of the mutant in this work supports the involvement of this gene in the metabolism of cholesterol in M. bovis BCG.

\section{MATERIALS AND METHODS}

\section{Bacterial Strains, Plasmids, and Growth Conditions}

The bacterial strains and plasmids used in this study are listed in Table 1. E. coli XL1 was used for cloning and plasmid propagation purposes and was cultured on solid or liquid LuriaBertani medium. M. bovis BCG Pasteur 1173P2 (BCGwt) and M. bovis BCG_2177::Tngfp (BCG-Tn) strains were routinely grown in $7 \mathrm{H} 9$ Middlebrook medium supplemented with $10 \%$ ADC and $0.05 \%$ Tween 80 or $7 \mathrm{H} 10$ Middlebrook medium supplemented with $10 \%$ OADC. When required, kanamycin (20 $\mathrm{\mu g} / \mathrm{ml})$, hygromycin $(50 \mathrm{mg} / \mathrm{ml})$, and sucrose $(2 \%)$ were added to the growth medium. To study the involvement of the BCG_2177c (specific-targeted loci and TetR-like gene) in mycobacterial cholesterol catabolism, BCGwt and BCG-Tn were grown in Dubos broth (Difco ${ }^{\mathrm{TM}}$ ) supplemented with 10\% ADC to reach an optical density of 0.5 at $600 \mathrm{~nm}\left(\mathrm{OD}_{600}\right)$. This culture was used (1:10 dilution) to inoculate (i) Dubos broth 
TABLE 1 | Characteristics of bacterial strains and plasmids used in this study.

\begin{tabular}{|c|c|c|}
\hline Strains & Characteristics & Reference/Source \\
\hline E. coli XL1 & recA1 laclq lacZ $\Delta M 15 T v 10$ & Sambrook et al., 1989 \\
\hline M. bovis BCG Pasteur & Vaccine strain 1173P2 & Institute Pasteur Collection \\
\hline \multicolumn{3}{|l|}{ Plasmids } \\
\hline pBlueScript SK & Polylinker in lacZ gene and $\mathrm{Amp}^{\mathrm{R}}$ & Stratagene \\
\hline pPR27 & Ts, ori myco, sacB gene & Pelicic et al., 1997 \\
\hline pKEN-mut2 & Vector containing gfp gene & Cormack et al., 1996 \\
\hline pPEP1 & pBlue Script SK+gfp gene whithout promoter & This work \\
\hline pPEP3 & pBlue Script+ derivated of Tn5367 & This work \\
\hline pEZ120 & $\mathrm{pEP} 1+\mathrm{IR}$ & This work \\
\hline pEZ121 & pEZ120 + frag Spel of pEP3 & This work \\
\hline pEZ123 & pPR27 Xbal + Tngfp & This work \\
\hline
\end{tabular}

base (without glycerol; BD Difco) containing 0.5\% bovine serum albumin (BSA; fraction V, Sigma) and supplemented with $0.01 \%$ cholesterol [a $5 \%$ cholesterol stock was obtained by dissolving the sterol in 1:1 (v/v) tyloxapol-ethanol mixture, followed by heating for $5 \mathrm{~min}$ at $80^{\circ} \mathrm{C}$ ], or (ii) Dubos medium with $10 \%$ ADC enrichment. Cultures were grown with agitation at $200 \mathrm{rpm}$ at $37^{\circ} \mathrm{C}$, and growth was monitored by measuring the $\mathrm{OD}_{600}$ and colony forming units per $\mathrm{ml}(\mathrm{CFU} / \mathrm{ml})$.

\section{Construction of Transposon Tngfp Delivering System (pEZ123)}

To generate pEZ123, plasmid pKen, containing gfp-mut2 gene (Cormack et al., 1996) was digested with XbaI and PstI and filled with Klenow. A $0.7 \mathrm{~kb}$ fragment containing promoter-less $g f p$ gene was ligated to pBlueScriptSK-linearized with SmaI to make pEP1 (Table 1 and Figure 1A). The plasmid pEP1 was further digested with HindIII and PstI and ligated to the synthetic IR from IS1096, constructed by annealing the oligonucleotides IR1 and IR2 (Table 2A), (with HindIII and PstI sites in the end) to make pEZ120. This plasmid was digested with SpeI and ligated with fragment SpeI from pEP3 to form pEZ121. pEP3 is a derivative of pBluescript containing transposon Tn5367. The transposon resultant in pEZ121 was named Tngfp. The fragment $\mathrm{XbaI}$ from pEZ21 containing Tngfp was ligated to pPR27 (Pelicic et al., 1997) linearized with XbaI. The resultant plasmid was named pEZ123 (Table 1 and Figure 1B).

\section{Introduction of Tngfp in M. bovis BCG and Construction of Mutant Library}

To produce insertion mutants, pEZ123 was introduced into M. bovis BCG by electroporation (Parish and Stoker, 1998). Cells were grown in plates with kanamycin at $32^{\circ} \mathrm{C}$. Then single colonies were grown in broth at $32^{\circ} \mathrm{C}$ to allow transposition and subsequently plated on kanamycin- (selecting transposon presence) and sucrose-containing medium plates at $39^{\circ} \mathrm{C}$, which are conditions not permissive for plasmid replication (Pelicic et al., 1997), allowing us to obtain the transposition mutants.

\section{Analysis of Mutants}

The colonies that survived at $39^{\circ} \mathrm{C}$ on plates with sucrose and kanamycin were analyzed in order to detect transposition events.
Mutant DNA digested with BamHI enzyme generates an internal fragment of the transposon, equal for all mutants, and two variable fragments depending on the region where the transposon was inserted (Figure 2A). Some colonies of $M$. bovis BCG were analyzed by Southern-blot (Figure 2B) and Ligation-Mediated PCR (LMPCR; Prod'hom et al., 1998).

All DNA manipulations, restriction enzyme digestions, agarose gel electrophoresis and Southern hybridizations were performed following standard procedures (Sambrook et al., 1989).

\section{Analysis of the Mutant Library by Flow Cytometry}

The mutant libraries of $M$. bovis BCG were grown up at exponential phase, harvested by centrifugation, washed with PBS and resuspended in the same buffer. The bacterial suspensions were analyzed by flow cytometry (Coulter Epic "Elite"). Approximately 10.000 individual events were excited at $488 \mathrm{~nm}$ prior analysis.

\section{Isolation of $M$. bovis BCG Mutants Using Fluorescence Activated Cell Sorter (FACS)}

To identify mycobacterial genes putatively involved in dormancy, the different pools of colonies from the M. bovis BCG::Tngfp library were grown up to stationary phase, then flow cytometry was used to sort out cells by fluorescence emission. Bacteria from the M. bovis BCG::Tngfp library were analyzed and sorted. After growth in 7H9 medium to stationary phase, BCG::Tngfp cells were harvested and washed two times in 1X PBS. After the final wash bacteria pellets were resuspended in PBS (approx. $10^{6}$ bacteria/ml) and analyzed by FACS (Coulter Epics Elite sorter. Hielary Fl, USA). To do so, the pellet of bacteria was excited with 488-nm laser and $530 \mathrm{~nm}$ was applied for detection. Up to 3000 cells per second of sorting was used. One cycle of flow cytometric cell sorting was performed to select bacteria showing high levels of fluorescence. Bacteria exhibiting high levels of fluorescence were collected and were plated directly on 7H10 solid medium containing kanamycin to recover individual clones. 
A

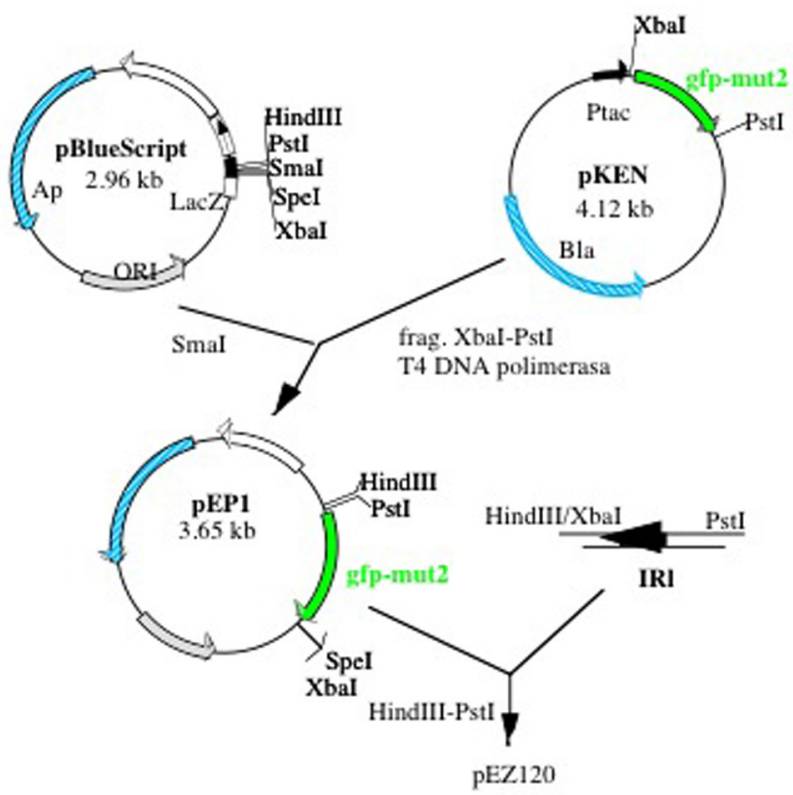

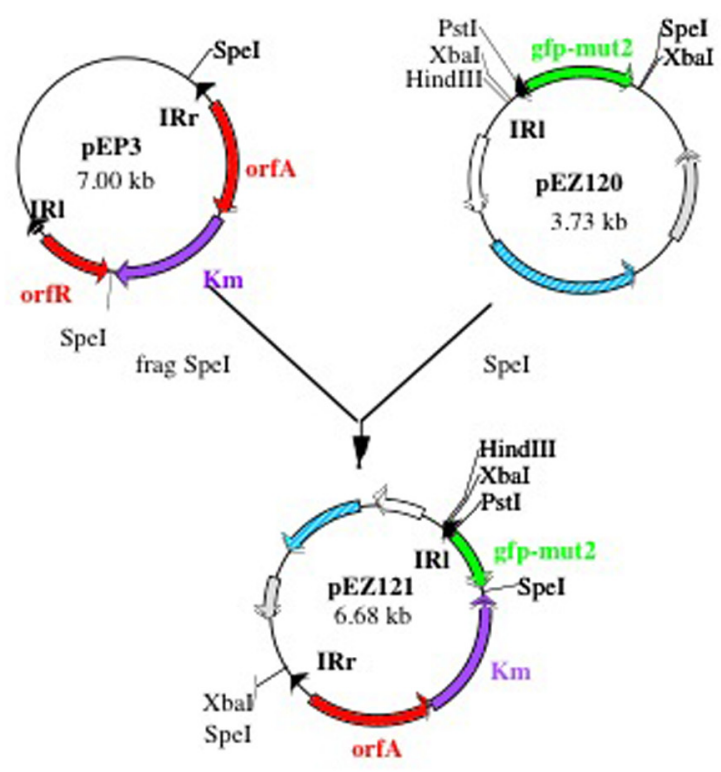

B

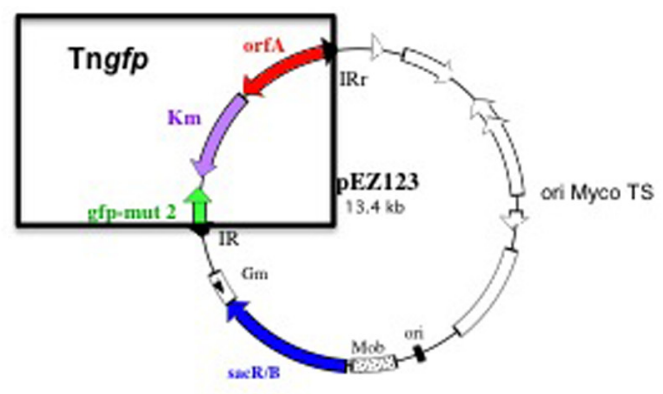

FIGURE 1 | Schematic diagram showing the construction of Tngfp delivering system pEZ123. (A) Construction of pEZ121 containing Tn5367 derivative with gfp reporter gene (Tngfp). (B) Map of the plasmid pEZ123 containing Tngfp. This plasmid was used for the construction of the libraries of mutants of Mycobacterium bovis BCG. Delivering system is based on a thermosensitive and sensitive to sucrose mycobacterial plasmid. Construction is described in material and methods.

Different colonies were re-isolated and analyzed by LMPCR (Prod'hom et al., 1998) to identify transposon insertion sites.

\section{Location of Tngfp Insertion Sites}

In order to study Tngfp insertion sites LMPCR was used according to the protocol described by Prod'hom et al. (1998). This technique allowed the amplification of both ends of the transposon. Briefly, the DNA was digested with the SalI enzyme, the fragments of DNA were ligated with an adapter Sal, containing Salgd and Salpt sequences (Table 2A), and the resulting template was then digested with SalI. The PCR was performed using IS2 and gfp1 primers (specific for Tngfp and directed outward) and the common linker primer Salgd (Table 2A). DNA was denatured by incubating the mixture at $95^{\circ} \mathrm{C}$ for $5 \mathrm{~min}$. Amplification was achieved using 35 cycles of PCR $\left(95^{\circ} \mathrm{C}\right.$ for $30 \mathrm{~s}$, specific annealing temperature for $30 \mathrm{~s}$ and $72^{\circ} \mathrm{C}$ for $90 \mathrm{~s}$ ), followed by a final extension at $72^{\circ} \mathrm{C}$ for $10 \mathrm{~m}$. Amplified products were separated by standard horizontal gel electrophoresis in a $1.5 \%$ agarose gel in TBE buffer $(90 \mathrm{mM}$ Tris,
$90 \mathrm{mM}$ boric acid, and $2 \mathrm{mM}$ EDTA) and were stained using ethidium bromide. PCR products were purified using the GFX ${ }^{\mathrm{TM}}$ PCR DNA and Gel Band Purification kit (Amersham Pharmacia Biotech Inc.) followed by ExoSAP-IT ${ }^{\circledR}$ PCR product clean up (Affymetrix).

The amplified products were sequenced with the corresponding oligonucleotides using $\mathrm{CNIO}^{3}$ service and further checked for homology at Tuberculist ${ }^{4}$, Bovilist ${ }^{5}$ and $\mathrm{NCBI}^{6}$ database BLAST analysis.

\section{Microscopy Analysis}

Mycobacterial cells were recovered from Dubos medium containing either dextrose or cholesterol at days 7 and 30, and were concentrated by centrifugation. Twenty microliter of each sample were smeared on three different slides, which were stained

\footnotetext{
${ }^{3}$ https://www.cnio.es/

${ }^{4} \mathrm{http}: / / g e n o l i s t . p a s t e u r . f r / T u b e r c u L i s t$

${ }^{5}$ http://genolist.pasteur.fr/BoviList

${ }^{6}$ http://www.ncbi.nlm.nih.gov/
} 
by Ziehl-Neelsen and with either, Auramine-O (Tec-Lam SA) or Nile Red (Sigma-Aldrich), following a previously published protocol (Deb et al., 2009). Microscopy for the fluorescencebased experiments was performed with an ECLIPSE Ti-Nikon's microscope. Images were acquired using a Nikon Intensilight C-HGFI digital camera. All magnifications were carried out with a 100X oil-immersion objective.

\section{Mycobacterial RNA Isolation}

Total RNA was isolated from cultures at the exponential and stationary phases as previously described (Gonzalez-y-Merchand et al., 1997). Briefly, cultures were harvested by centrifugation and pellets were resuspended in guanidinium chloride buffer $(6 \mathrm{M}$ guanidinium chloride, $0.1 \%$ Tween $80,1 \mathrm{mM} 2$-mercaptoethanol, $10 \mathrm{mM}$ EDTA) in a proportion of $1 \mathrm{ml}$ of buffer/100 $\mathrm{ml}$ of culture. Cells were lysed mechanically in a FastPrep (Thermo Scientific) with 150 - to $200-\mu \mathrm{m}$ glass beads (Sigma-Aldrich) by performing four lysis cycles of $15 \mathrm{~s}$ each at high speed $(6.5 \mathrm{~m} / \mathrm{s})$. Nucleic acids were purified with phenol-chloroform-isoamylic alcohol (25:24:1), and RNA was differentially precipitated with 0.4 volume of absolute ethanol (added drop by drop).

Finally, RNA was washed three times with Trizol reagent (Invitrogen). RNA integrity was analyzed with a bioanalyzer (Agilent technologies) and quantified by spectrophotometry with a NanoDrop ND-1000 (Thermo Scientific).

\section{qRT-PCR of Selected Genes and Non-coding RNAs}

Transcription levels of several selected targets were measured by using real-time quantitative RT-PCR. Quantification was carried out with specific primers (Table 2B) and Light Cycler FastStart DNA SYBR green (Roche). Samples were subjected to 1 cycle at $95^{\circ} \mathrm{C}$ for $60 \mathrm{~s}$ (to activate the enzyme) followed by 40 cycles of amplification (denaturation at $95^{\circ} \mathrm{C}$ for $0 \mathrm{~s}$, specific annealing temperature for $5 \mathrm{~s}$, and extension at $72^{\circ} \mathrm{C}$ for $10 \mathrm{~s}$ ) with a final extension at $72^{\circ} \mathrm{C}$ for $10 \mathrm{~min}$. A melting curve analysis was performed to determine the specificity of the amplified product.

TABLE 2 | Oligonucleotides used in this study.

(A) Oligonucleotides used for the construction and study of Tngfp mutant library.

\begin{tabular}{|c|c|c|}
\hline Target & Oligonucleotide Sequence $\left(5^{\prime}-3^{\prime}\right)$ & Reference \\
\hline \multirow[t]{2}{*}{ Insertion site } & Salgd: TAGCTTATTCCTCAAGGCACGAGC & Prod'hom et al., 1998 \\
\hline & Salpt: TCGAGCTCGTGC & \\
\hline \multirow[t]{2}{*}{ Tngfp } & IS2: GAGGCGGCAGAAAGTCGTCAGGTCAG & This work \\
\hline & gfp1: TCCTTCTTAAATCTAGGGCTGCAG & \\
\hline \multirow[t]{3}{*}{ Inverted Repeat (IR) } & IR1: AAGCTITCTAGAGGCTCTTCGCACTTGACGGTGTAGAGACGATCAGCTG & This work \\
\hline & CIIICGCGCIGAAGCII & \\
\hline & $\begin{array}{l}\text { IR2: TGCAGATCACAGCGGAAAGCAGCTGATCGTCTCTACACCGTCAAGTGCGAAGAGCC } \\
\text { TCTAGAAGCTा }\end{array}$ & \\
\hline
\end{tabular}

(B) Oligonucleotides used for Real Time quantitative PCR (RT-qPCR) experiments*.

\begin{tabular}{|c|c|c|c|}
\hline Target & Oligonucleotide Sequence $\left(5^{\prime}-3^{\prime}\right)$ & $\mathbf{T}^{\circ} \mathbf{C}$ ann. & Reference \\
\hline \multicolumn{4}{|c|}{ 16S ribosomal RNA } \\
\hline \multirow[t]{2}{*}{$\operatorname{rrs}(16 \mathrm{~S}$ rDNA) } & 16S TB-F: ATGACGGCCTTCGGGTTGTA & $66^{\circ} \mathrm{C}$ & Cubero et al., 2013 \\
\hline & 16S TB-R: CGTATTACCGCGGCTGCTGGCAC & & \\
\hline \multicolumn{4}{|l|}{ Genes } \\
\hline \multirow[t]{2}{*}{$\operatorname{tgs} 1$ (Rv3130c) } & tgs1-F: TTGCCACCCGCCTTCC & $50^{\circ} \mathrm{C}$ & This work \\
\hline & tgs1-R: TCGCCACGGTGACAACA & & \\
\hline \multirow[t]{2}{*}{ Itp2 (Rv3540c) } & Rv3540c-F: GTATCGGGCATTCAACGAAC & $55^{\circ} \mathrm{C}$ & This work \\
\hline & Rv3540c-R: GTGCGGATACGAAAACGAAT & & \\
\hline \multirow[t]{2}{*}{ yrbE4A (Rv3501c) } & Rv3501c-F: CTACGCGTTCTCGGTCTITC & $55^{\circ} \mathrm{C}$ & This work \\
\hline & Rv3501c-R: AGTATCAATTCGCGCAGTCC & & \\
\hline \multirow[t]{2}{*}{ murE (Rv2158c) } & Rv2158c-F: CGCCTTCACCAATCTCTCC & $55^{\circ} \mathrm{C}$ & This work \\
\hline & Rv2158c-R: AGTCCGGATCGAACAATGAC & & \\
\hline \multicolumn{4}{|l|}{ Small RNAS } \\
\hline \multirow[t]{2}{*}{ MTS2823 } & MTS2823-F: GAGAAGGTTCGGTCTCCCGAC & $58^{\circ} \mathrm{C}$ & This work \\
\hline & MTS2823-R: TTACGCAGACCCGCAACACT & & \\
\hline \multirow[t]{2}{*}{ MTS0997 } & MTS0997-F: AAGCAGGCCCGGTTAGTGA & $58^{\circ} \mathrm{C}$ & This work \\
\hline & MTS0997-R: CACCGGTACACATGGGCAGA & & \\
\hline \multirow[t]{2}{*}{ rnpB } & rnpB-F: TTCACAGAGCAGGGTGATTG & $62^{\circ} \mathrm{C}$ & This work \\
\hline & rnpB-R: CTCTTACCGCACCGTITCAC & & \\
\hline
\end{tabular}

*The sequences of M. tuberculosis H37Rv and M. bovis BCG Pasteur are identical in all the genes and genomic regions under study. 


\section{A}
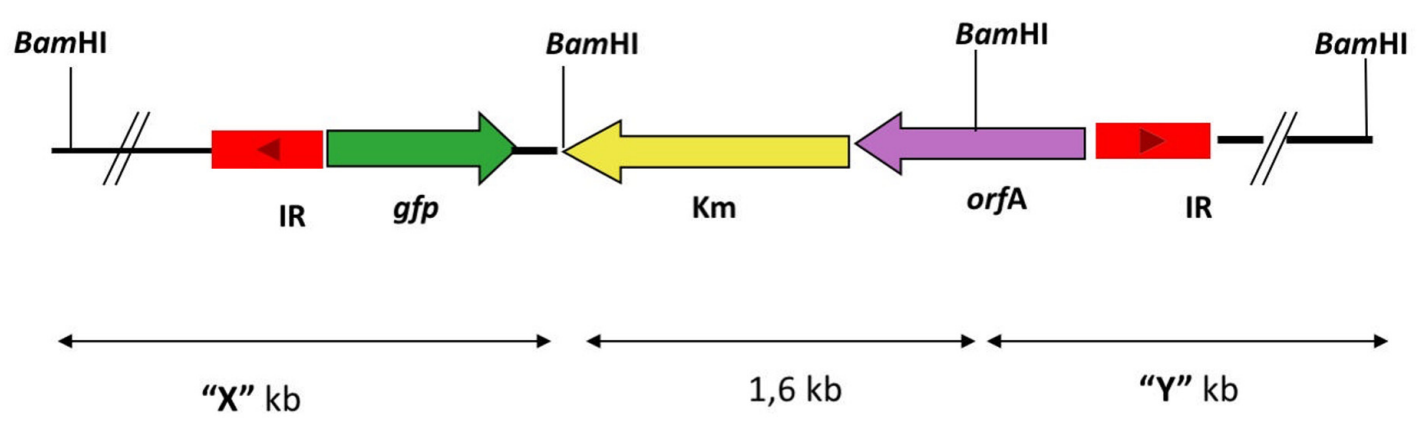

B

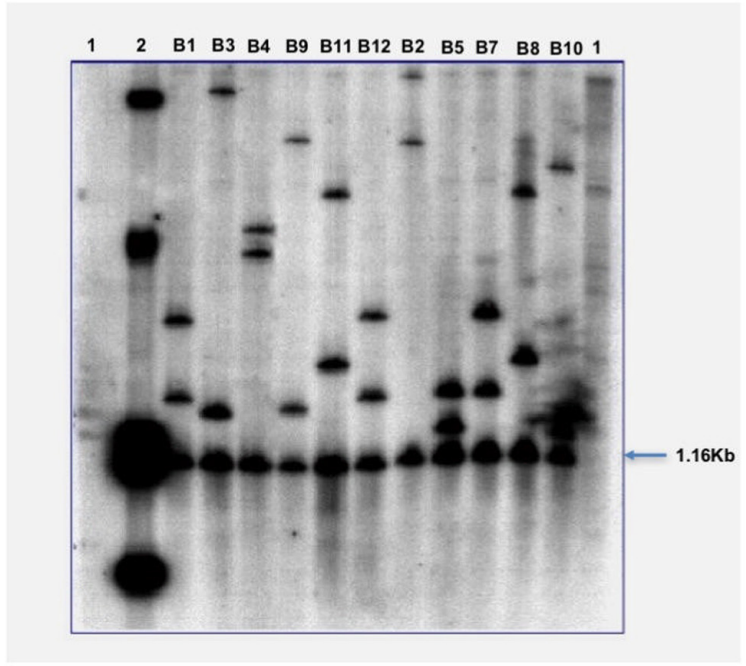

C

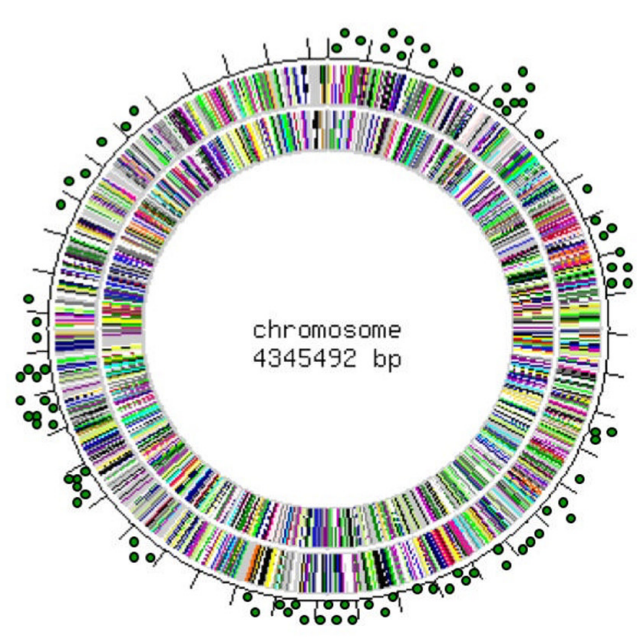

FIGURE 2 | Results of the Tngfp transposition. M. bovis BCG mutants analyzed by enzymatic digestion and then hybridized with a transposon probe. (A) Mutant DNA digested with BamHI enzyme, generates an internal fragment of the transposon (1.6 Kb), equal for all mutants, and two variable fragments depending on the region in which the transposon was inserted. (B) Southern-Blot analysis of $11 \mathrm{M}$. bovis BCG mutants. The DNA of colonies that had grown at $39^{\circ} \mathrm{C}$ with sucrose was digested with BamHI and hybridize with the Tngfp like probe. Lane 1, DNA from M. bovis BCG; Lane 2, Plasmid pEZ123; Lanes B1-B12 different mutants of M. bovis BCG. (C) Distribution of Tngfp through the M. bovis BCG genome. The obtained locations of the transposon were plotted in $M$. bovis BCG genome.

The standard curve was obtained for each pair of primers by using 10-fold dilutions of known amounts of $M$. tuberculosis H37Rv chromosomal DNA (nanograms of DNA per microliter). Threshold cycle values of each transcript quantified were interpolated to standard curve to measure the level of transcription. At least three amplifications per target were performed. Normalization of the data was performed by using $16 \mathrm{~S}$ rRNA levels.

\section{RESULTS}

\section{Construction of the Tngfp Delivery Plasmid pEZ123}

In order to obtain a library of mutants by transposition, containing a $g f p$ gene, acting as reporter gene, an artificial transposon containing two IR of IS1096 at both ends, was constructed as described in the Section "Materials and Methods"
(Figure 1A). The transposon, named Tngfp (Figure 1B), contains the orfA gene from Tn5397 (Mcadam et al., 1995), a kanamycinresistance gene and a promoterless copy of the gene encoding a mutated version of GFP (Cormack et al., 1996). This form of GFP exhibits greater fluorescence and solubility compared to the wildtype protein. Tngfp was cloned into the plasmid pPR27 (Pelicic et al., 1997), an Escherichia coli-Mycobacterium shuttle plasmid, which is thermosensitive and able to replicate in mycobacteria, contains the gentamicin resistance gene and contains the $\operatorname{sac} B$ gene as a counter selectable marker. The resulting deliverable vector containing Tngfp was named pEZ 123 (Figure 1B).

\section{Tngfp Mutagenesis Library in M. bovis BCG}

To determine the functional activity of Tngfp, pEZ123 (Figure 1B) was introduced in the slow growing non-pathogenic mycobacteria $M$. bovis BCG. After growing on kanamycin and 


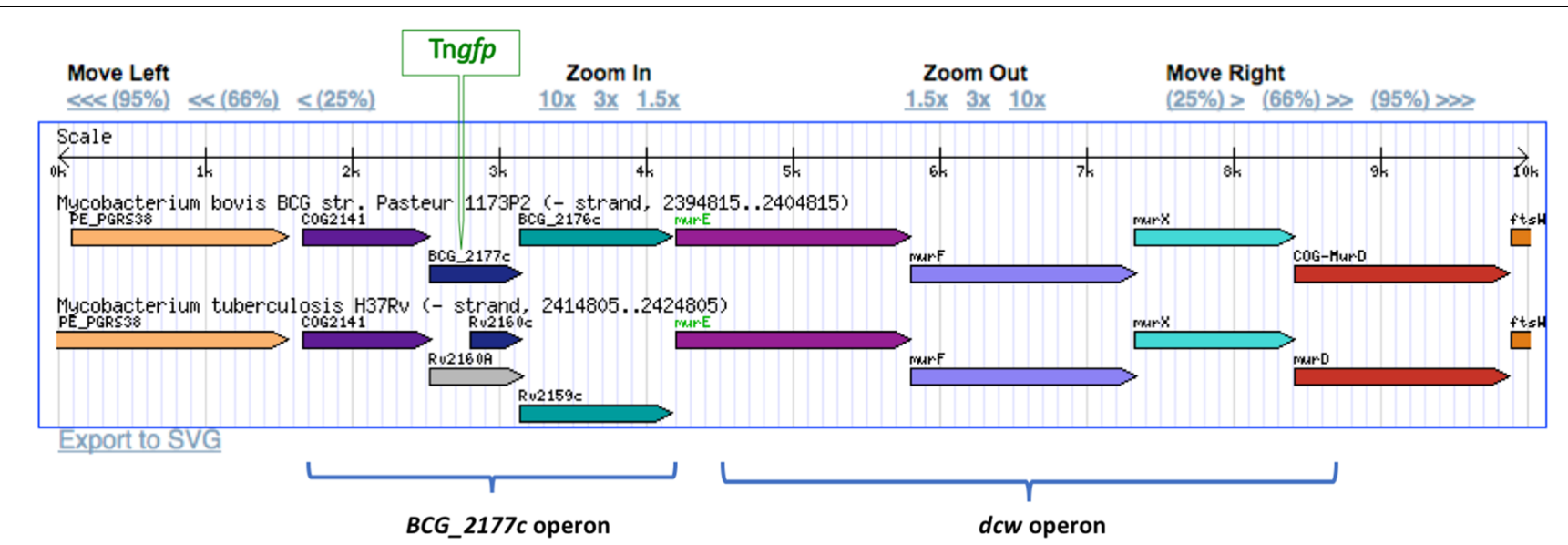

FIGURE 3 | Location of Tngfp in BCG_2177c gene in the $\boldsymbol{M}$. bovis BCG genome. BCG_2177c gene is located upstream from the division cell wall gene cluster $(d c w)$. The insertion of Tngfp was in the same orientation that replication $d c w$ genes. Gene members of the $d c w$ operon as well as genes of the same operon that BCG_2177c were indicated.

\section{Stationary phase of growth}

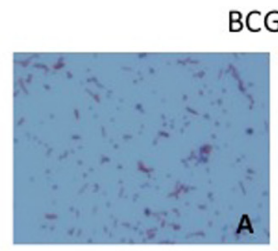

CGwt
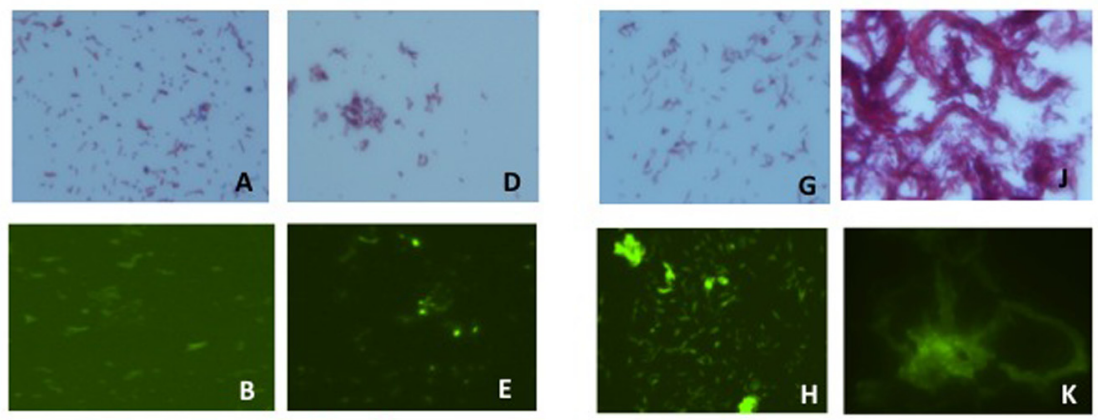

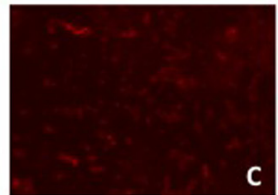

Dextrose

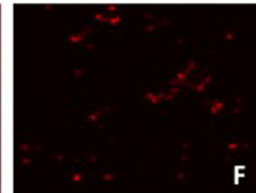

Cholesterol

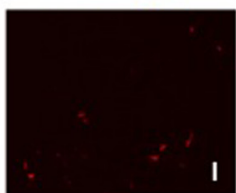

Dextrose

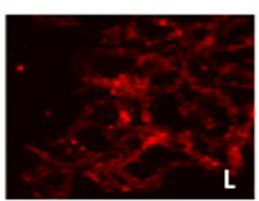

Cholesterol

FIGURE 4 | Morphological changes of BGC wt and BCG-Tn during stationary phase in the presence of different carbon sources. Morphological changes in stationary phase of mycobacterial cultures after growth in the presence of dextrose (A-C) and (G-I) or cholesterol (D-F) and (J-L) as carbon sources. BCGwt (A-F) or BCG-Tn (G-L) cells were harvested from the corresponding cultures and stained by Ziehl-Neelsen (A,D,G,J) or with Auramine (B,E,H,K) or Red Nile $\mathbf{( C , F , I , L ) ~ t h e ~ t w o ~ l a s t ~ b y ~ f l u o r e s c e n t ~ m i c r o s c o p y . ~ C o r d - l i k e ~ s t r u c t u r e s ~ a r e ~ o b s e r v e d ~ i n ~} \mathbf{( J - L )}$ panels, corresponding to stationary phase of the mutant growing in cholesterol. All magnifications were carried out with the 100X oil immersion objective.

sucrose containing medium at $39^{\circ} \mathrm{C}$, we selected transposition mutants. A transposon mutagenesis library with Tngfp in BCG was constructed. We prepared an ordered library consisting of independent 5664 kanamycin, sucrose and thermoresistant mutants. The library was assembled into 40 pools. To verify that the transposition library was representative, some M. bovis BCG mutants were analyzed by digestion and then hybridized with the transposon. Mutant DNA digested with BamHI enzyme, generates an internal fragment of the transposon, equal for all mutants, and two variable fragments depending on the region where the transposon was inserted (Figure 2A). Southern blot analysis of randomly selected colonies for 11 mutants showed that each of them contained a single transposon insertion that produced a unique restriction fragment pattern (Figure 2B). We also analyzed 150 mutants from the ordered library by LMPCR technique. By sequencing the transposon flanking 
A

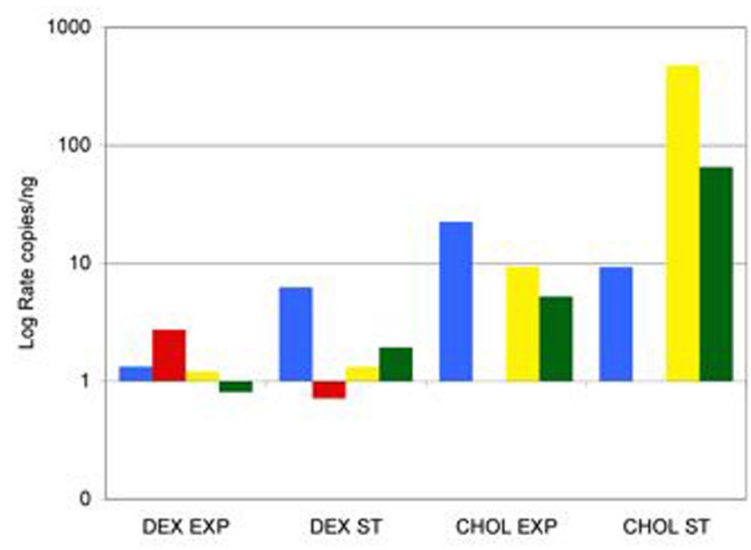

\begin{tabular}{|c|c|c|c|c|}
\cline { 2 - 5 } \multicolumn{1}{c|}{} & DEX EXP & DEX ST & CHOL EXP & CHOL ST \\
\hline murE & 1.32 & 6.22 & 22.37 & 9.22 \\
\hline tgs1 & 2.72 & 0.71 & UDL & UDL \\
\hline Itp2 & 1.20 & 1.32 & 9.32 & 474.68 \\
\hline yrbE4 & 0.81 & 1.92 & 5.20 & 65.10 \\
\hline
\end{tabular}

B

BCG-Tn / BCGwt

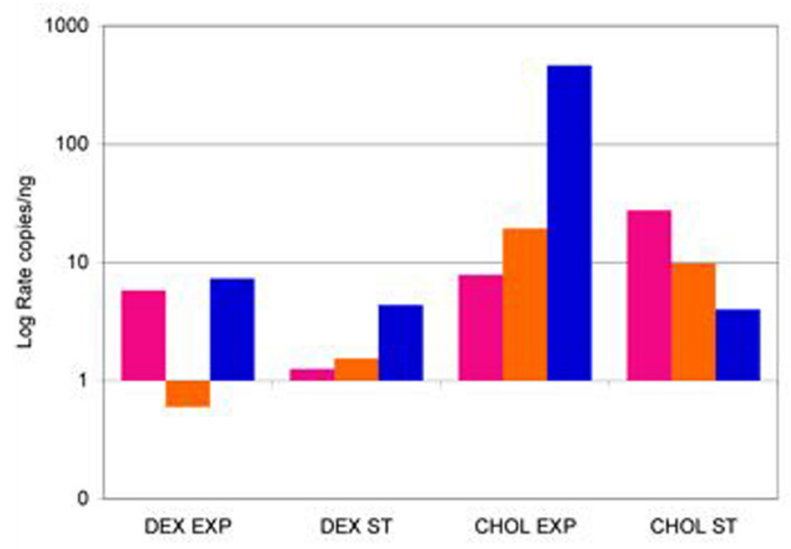

\begin{tabular}{|c|c|c|c|c|}
\cline { 2 - 5 } \multicolumn{1}{c|}{} & DEX EXP & DEX ST & CHOL EXP & CHOL ST \\
\hline MTS2823 & 5.78 & 1.25 & 7.78 & 27.43 \\
\hline MTS0997 & 0.59 & 1.53 & 19.17 & 9.78 \\
\hline rnpB & 7.29 & 4.34 & 460.39 & 3.99 \\
\hline
\end{tabular}

FIGURE 5 | Differential expression of selected genes and ncRNA in $\mathbf{M}$. bovis BCG (BCGwt and BCG-Tn). Level of expression of BCG wt versus BCG-Tn of (A) murE, tgs1, Itp2, and yrbE4A genes; and (B) MTS2823, MTS0997, and rnpB ncRNAs. Log rate of number of copies/ng of the mutant BCG-Tn and BCGwt were calculated in different conditions of culture (Dextrose: DEX; Cholesterol: $\mathrm{CHOL}$ ) and growing phases (Exponential: EXP; Stationary: ST). The data were normalized with the expression of rrs gene coding for 16S-rRNA. UDL, under detection level. Complete set of data is showed in Supplementary Figures S4, S5.

regions, we identified 77 different points of transposon insertion (Supplementary Table S1). The obtained locations of the transposon were plotted in the M. bovis BCG genome showing a distribution through the entire chromosome length (Figure 2C). Sequencing of the insertion junctions of the 77 mutants revealed that $66(85.7 \%)$ insertions were found within ORFs and 11 were intergenic regions (Supplementary Table S1).

\section{Flow Cytometry Analysis of the Tngfp M. bovis BCG Libraries}

To determine if the M. bovis BCG mutant library was useful to differentiate populations of fluorescent bacteria, the library was analyzed by flow cytometry. Only $3.65 \%$ of the M. bovis BCG mutants in the library showed detectable fluorescence levels (Supplementary Figure S1A).

Aiming to select transposition mutants putatively involved in dormancy, further analyses were performed to detect $M$. bovis BCG::Tngfp cells exhibiting high levels of fluorescence at stationary phase by using FACS. Up to 23 colonies were reisolated and analyzed by LMPCR to localize the transposon insertion site. From these, only mutants where the orientation of $g f p$ and the neighbor gene was the same were selected. One of those mutants showed GFP expression level more than 20fold compared to other mutants. GFP production was maximal at stationary phase (Supplementary Figure S1B). This mutant was identified as carrying the transposon inserted 56 nucleotides inside from start codon of the $2177 \mathrm{c}$ gene of $M$. bovis BCG, which is part of an operon located immediately upstream of the $d c w$ operon (Figure 3), the last known to be involved in cell division and cell wall formation in M. tuberculosis (Munshi et al., 2013).

BCG_2177c has been reported to be homologous to Rv2160A of $M$. tuberculosis, identified as a member of the TetR-family of transcriptional regulators, which have been related to the regulation of genes involved in cholesterol metabolism (Casabon et al., 2013).

\section{Growth of BCG-Tn in Cholesterol}

In order to determine the influence of cholesterol on the growth of (BCG-Tn), we cultured BCGwt and its mutant in a medium supplemented with cholesterol as a sole carbon source. Growth in cholesterol was compared to growth in dextrose (control medium). We found similar growth profiles measured by CFUs for those mycobacteria independent of the carbon source used (Supplementary Figure S2B). Some differences were found in the growth profiles measured by OD. For example, the exponential phase slopes of the wild type strain and its corresponding mutant were very similar in the presence of cholesterol (Supplementary Figure S2A) and both strains reached the stationary phase at the same time (day 4 ). In contrast, when both mycobacteria were grown in the presence of dextrose, BCG-Tn showed an exponential phase delay, compared with wild type, and it approximately reached only half of the cell density (in relation to wild type) at the end of stationary phase. The influence of cell aggregation in the OD results cannot be discarded. 
The effect of cholesterol on the microscopic morphology of BCG wild type and BCG-Tn mutant was analyzed at exponential and stationary growth phases. Both strains were tested and their growth in dextrose and cholesterol were also compared (Figure 4 and Supplementary Figure S3). When both strains were cultured in the presence of cholesterol, an accumulation in the lipid content was shown, by Nile Red stain, compared to the cultures in dextrose. During the exponential phase of growth, no differences were detected comparing wild-type and mutant by Ziehl-Neelsen, Auramine or Red Nile stains (Supplementary Figure S3). In contrast, strong cord formation was identified at the stationary phase when the mutant was grown in cholesterol (Figures 4J-L). In addition, cell aggregation was also found in the wild-type growing in cholesterol at stationary phase (Figures $4 \mathrm{D}-\mathrm{F}$ ). The aggregates or cords were not present in stationary phase when wild-type and mutant were grown in dextrose (Figures 4AC,G,H).

\section{Gene Expression of $M$. bovis BCG-Tn in Cholesterol}

To gain insights into the influence of the transposon on gene expression related to cholesterol metabolism, several genes were quantitatively analyzed from cultures recovered at exponential and stationary phases of growth. Genes related to cholesterol metabolism such as $l t p 2$, a probable lipid transfer protein, and $y r b \mathrm{E} 4 \mathrm{~A}$, a possible $\mathrm{ABC}$ transporter, both putatively involved in cholesterol intake, were studied. Apart from tgsl, a central gene in the lipid metabolism and murE, the gene leading the $d c w$ operon located downstream of the transposon insertion was also studied. Comparisons were made between BCGwt and BCG-Tn growing with and without cholesterol as a sole carbon source. Moreover, cultures were recovered at exponential and stationary phases of growth in each culture condition.

Figure 5 showed the ratio of gene expression comparing mutant versus wt bacteria. The level of expression of murE was higher in the mutant, particularly when bacilli grew in cholesterol and during exponential phase. Genes related to cholesterol metabolism, namely ltp2 and $y r b \mathrm{E} 4 \mathrm{~A}$, also showed higher expression in the mutant compared to the wt when bacteria grew with cholesterol, with a more marked increase observed during stationary phase (Figure 5A). These results could suggest a repressor activity of the tetR-like gene over those genes, being that activity enhanced in the presence of cholesterol. On the contrary, the level of expression of tgs 1 was lower in dextrose and stationary phase in the mutant compared to the wt. This gene was undetectable in the mutant when the bacteria grew in cholesterol (Figure 5A).

Detection of non-coding RNAs was also performed (Figure 5B). With few exceptions, the three non-coding targets showed higher expression in the mutant compared to the wt, both in dextrose as well as in cholesterol. The noncoding $r n p \mathrm{~B}$, involved in tRNA maturation was 400 -fold more expressed in the mutant during exponential phase in cholesterol (Figure 5B).
The complete set of qRT-PCR normalized data of the targeted genes and the targeted non-coding RNAs, are presented in Supplementary Figures S4, S5, respectively.

\section{DISCUSSION}

Since transposition was first demonstrated in fast growing mycobacteria with IS6100 (Martin et al., 1990), other mycobacterial ISs, not presents in M. tuberculosis, have been demonstrated to be active in mycobacteria (Mcadam et al., 2000). Transposons derived from the M. smegmatis insertion sequence IS1096 (Cirillo et al., 1991) were modified for its use in slow-growing mycobacteria by the insertion of a kanamycin resistance cassette showing to be active in $M$. bovis BCG and in several strains of $M$. tuberculosis and $M$. paratuberculosis (Mcadam et al., 1995; Bardarov et al., 1997; Pelicic et al., 1997; Harris et al., 1999). After those developments, transposon mutagenesis was available in mycobacteria allowing for the preparation of transposon-mutant libraries, in such a way that phenotypic screening on a large scale could be undertaken, including the study of genes required for pathogen adaptation to a host by using signature-tagged mutagenesis (Camacho et al., 1999; Cox et al., 1999).

The use of fusions with reporter genes might enable the identification of genes that were differently expressed under specific conditions (Machowski et al., 2000; Dandie et al., 2006). The $g f p$ gene is a useful reporter for in vivo studies because no substrate is required for the detection of its fluorescent product (Valdivia and Falkow, 1998). Previous studies allowed the detection of promoters through detection of an increase expression of $g f p$ in M. tuberculosis and M. bovis BCG (Triccas et al., 1999) or M. marinum (Barker et al., 1998) growing inside macrophages. In our work, intracellular levels of GFP were found to be 2-20 times higher than that found in previous in vitro cultures of those mycobacteria performed in the laboratory (data not shown).

In this work, we have developed a new artificial transposon suitable to generate expression libraries of the GFP fluorescent protein in mycobacteria. We have tested the transposition driven by Tngfp as a rapid method to generate multiple insertions into the chromosome of $M$. bovis BCG, and we constructed a comprehensive bank of 5664 insertion mutants using a new transposon mutagenesis system. Moreover, analysis by flow cytometry provided high sensitivity allowing the detection of fluorescent bacteria, even with a single copy of $g f p$ per genome, therefore it was useful for the screening of $M$. bovis BCG transposon mutant libraries under different conditions.

A wide range of different insertion sites were identified in M. bovis BCG (up to 77/150 clones). When, we analyzed the transposon insertion points of these mutants we observed that transposition occurred randomly (Figure 2C and Supplementary Table S1). No consensus sequence was identified as a target for this transposon. Remarkably, $85,7 \%$ of the insertions happened in coding regions. The suitability of the procedure to generate a representative library could be inferred taking into consideration that: (1) $91 \%$ of $M$. tuberculosis genome corresponds to 
open reading frames (Cole et al., 1998); and (2) when the transposon disrupts an essential gene such a mutant will not be obtained. In addition, genes interrupted by Tngfp are distributed among the different functional categories in the BCG genome, similarly to the proportional distribution in the genome of M. tuberculosis ${ }^{7}$. Other studies of transposition in vivo (using IS6110) reported only 50\% transposon insertion within coding regions in $M$. tuberculosis and in $M$. bovis strains (Mendiola et al., 1992; Otal et al., 2008; Alonso et al., 2013).

In searching for transposition events in loci putatively related to dormancy, the fluorescent level of M. bovis BCG::Tngfp cells were studied in stationary phase and analyzed by flow cytometry. Using this procedure, a mutant targeting the gene BCG_2177c (named BCG-Tn) was detected. This transposon mutant showed approximately 20 times higher fluorescent levels at stationary phase compared to other mutants tested (data not shown).

BCG_2177c is homologous to M. tuberculosis Rv2160A, a gene identified in $M$. tuberculosis with similarities to the TetR-family of transcriptional regulators. TetR is a large family of transcriptional regulators known to be involved in many metabolic routes in bacteria (Ramos et al., 2005). Some members of this family were involved in the metabolism of cholesterol (Klepp et al., 2012). The genome of $M$. tuberculosis encodes for a high number of genes involved in the catabolism of cholesterol (Ouellet et al., 2011), a main carbon source of the tubercle bacilli during infection, including latent infection (Miner et al., 2009).

To gain insights into the role that BCG_2177c could play in M. bovis BCG, BCG-Tn mutant and BCG wt were studied in more detail during their growth in cholesterol. Growth curves of both bacteria in cholesterol or dextrose as main carbon sources showed an impaired growth in dextrose of the mutant compared to $w t$ (Supplementary Figure S2). On the other hand, a particular morphological change was observed in the mutant during stationary phase in cholesterol. Under this last condition, the BCG-Tn bacilli showed strong cord formation (Figures 4J-L), which was not observed in the mutant or in the $w t$ in any other condition. These findings suggest changes in the cell envelope of the bacteria possibly related to the targeted gene.

Notable was the increased level of the nc RNA, namely rnpB, in the mutant, during exponential phase growth in cholesterol (Figure 5). This non-coding RNA is a component of the RNase $\mathrm{P}$ and participates in the maturation of tRNAs (Herrmann et al., 2014). The involvement of tRNAs in changes at the cell wall level (Francklyn and Minajigi, 2010) suggests that a modification of such cell structures during the adaptation of the mutant to growth in cholesterol could putatively be related with the phenotypic changes of the mutant in stationary phase detected by acidfast and fluorescent staining (Figures 4J-L). Interestingly, this ncRNA seems to be essential for $M$. tuberculosis when the bacillus grows in cholesterol (Griffin et al., 2011).

To further analyze the influence of cholesterol in more detail, the transcriptomic patterns of selected genomic regions known to have some role in the infection of $M$. tuberculosis (Arnvig and Young, 2009; Miner et al., 2009) were studied. This was carried out in all four culture conditions. Results showed that genes

${ }^{7}$ http://genolist.pasteur.fr/TubercuList related to cholesterol metabolism (ltp2 and $y r b \mathrm{E} 4 \mathrm{~A}$ ) have roughly similar expression levels between mutant and $w t$ in dextrose, but their levels of expression increased in the mutant during growth in cholesterol, mainly at stationary phase (Figure 5A). These results suggested a putative repressor activity of BCG_2177c on those genes in the presence of cholesterol. It has been shown that $y r b \mathrm{E} 4$ expression is regulated by a TetR-family member (KstR) in M. tuberculosis (Ouellet et al., 2011). The expression level of the $y r b \mathrm{E} 4$ is not affected when $M$. tuberculosis is cultured in dextrose ${ }^{8}$; unfortunately, this effect is unknown in M. tuberculosis growing in cholesterol. Our results suggested that BCG_2177c could play a similar role in $M$. bovis BCG, and that influence appeared to be enhanced during growth in cholesterol.

The participation of the gene murE in the synthesis of the peptide-glycan, suggested a higher level of its expression when bacteria grows faster. As expected, according to Supplementary Figure S2, a higher level of expression of this gene was detected in cholesterol compared to dextrose in both strains. Compared to BCG $w t$, the level of expression detected for murE in the mutant BCG-Tn was high in all conditions, except dextrose at exponential phase (Figure 5A), a condition that causes an impaired growth of the mutant (Supplementary Figure S2). Whether this result was a direct consequence of the transposition event or not requires further studies.

An unexpected result was found for the gene $\operatorname{tgs} 1$, a main gene involved in dormancy that participates in the synthesis of triacylglycerol in $M$. tuberculosis. Comparing mutant and $w t$, this gene was similarly expressed in both strains during growth in dextrose, although it showed a slight level of increase in exponential phase in the mutant. However, its expression was undetectable in the mutant when cholesterol was used as a carbon source (Figure 5). Our results showed that the expression of $\operatorname{tgs} 1$ ceased when BCG_2177c was truncated after transposition, thus suggesting a direct or indirect participation of the BCG_2177c gene in the activation of $\operatorname{tgs} 1$ expression in $M$. bovis BCG during growth in cholesterol.

Finally, the expression of two other nc-RNAs was also analyzed in the mutant BCG-Tn and BCG wt under the four conditions studied (Figure 5B). The data showed a higher level of expression of the nc-RNAs in the mutant, when bacteria grew in cholesterol, particularly at stationary growth phase. This result was also found when M. tuberculosis was grown in long chainfatty acids as a sole carbon source (Rodriguez et al., 2014) thus suggesting a role of these two nc-RNAs during latent infection, a situation in which lipids, including cholesterol, seem to play an essential role in $M$. tuberculosis. Our results showed that BCG_2177c could play some role during a similar process in M. bovis BCG.

As described in this work, the transposon mutagenesis system has showed to be an excellent procedure in the study of gene function, even in fastidious bacteria such as mycobacteria. Our transposon Tngfp was shown to be active also in other mycobacteria, from the main pathogen $M$. tuberculosis to the saprophyte $M$. smegmatis, therefore this methodology could be putatively applied to the study of gene function in other members

\footnotetext{
${ }^{8}$ http://www.tbdb.org
} 
of the genus. Moreover, by application of the Tn-seq technique, this transposon system represents a valuable tool for a wider study of gene function in the genus.

Finally, limitations of the system exist, such as the lack of detection of low-level promoters or the lost of strong promoters due to deleterious effect of GFP accumulation. Likewise, the involvement of other regulators that may indirectly influence the changes detected cannot be discarded.

In summary, to the best of our knowledge, this work showed for the first time the usefulness of a transposon mutant library prepared with the promoterless gfp gene. We have showed that the novel transposon mutagenesis system developed in this study is a useful tool to analyze functional activity of targeted genes in M. bovis BCG. While further characterization is still required, our work also proposes the direct or indirect involvement of BCG_2177c gene in cholesterol metabolism of this vaccine strain, suggesting a role of this putative TetR gene during the survival of the strain in the human host, a cholesterol-enriched environment.

\section{AUTHOR CONTRIBUTIONS}

EP-H constructed the transposon, IO prepared and studied the M. bovis library and selecting the mutant. LG-M, JG-M, MM, and MG studied the mutant in cholesterol. IO, JG-M, MM, and MG wrote the manuscript. LG-M, EP-H, and CM contributed to the final draft and revision. All authors read and approved the manuscript.

\section{FUNDING}

This work was supported by "Spanish Ministry of Economy and Competitiveness" [grant number BIO2014-5258P]. We also acknowledge the "Gobierno de Aragón (DGA-GC B25)/Fondo Social Europeo” and Grant CB 2015-255181, CONACyT, México. JG-M held a sabbatical fellowship funded by the Spanish Ministry of Education [SAB2010-0102].

\section{REFERENCES}

Alonso, H., Samper, S., Martin, C., and Otal, I. (2013). Mapping IS6110 in highcopy number Mycobacterium tuberculosis strains shows specific insertion points in the Beijing genotype. BMC Genomics 14:422. doi: 10.1186/1471-2164-14-422

Arnvig, K. B., and Young, D. B. (2009). Identification of small RNAs in Mycobacterium tuberculosis. Mol. Microbiol. 73, 397-408. doi: 10.1111/j.13652958.2009.06777.x

Bach, E. A., Ekas, L. A., Ayala-Camargo, A., Flaherty, M. S., Lee, H., Perrimon, N., et al. (2007). GFP reporters detect the activation of the Drosophila JAK/STAT pathway in vivo. Gene Expr. Patterns 7, 323-331. doi: 10.1016/j.modgep.2006. 08.003

Balhana, R. J., Singla, A., Sikder, M. H., Withers, M., and Kendall, S. L. (2015). Global analyses of TetR family transcriptional regulators in mycobacteria indicates conservation across species and diversity in regulated functions. $B M C$ Genomics 16:479. doi: 10.1186/s12864-015-1696-9

Bardarov, S., Kriakov, J., Carriere, C., Yu, S., Vaamonde, C., Mcadam, R. A., et al. (1997). Conditionally replicating mycobacteriophages: a system for transposon

\section{ACKNOWLEDGMENTS}

We would like to thank to Ana Belen Gomez for technical support. We thank B. Sainz for his revision of the English style.

\section{SUPPLEMENTARY MATERIAL}

The Supplementary Material for this article can be found online at: http://journal.frontiersin.org/article/10.3389/fmicb. 2017.00315/full\#supplementary-material

FIGURE S1 | GFP expression of the $M$. bovis BCG library and $M$. bovis BCG-Tn. (A) Flow cytometry analysis of the library of $M$. bovis BCG mutants at logarithmic phase. A total of $3.65 \%$ of the mutants showed detectable fluorescence level. (B) Histograms obtained by flow cytometry at four different points of the growth curve of the mutant $M$. bovis BCG-Tn. The expression level of gfp at stationary phase (days 32 and 64 of growth) was much higher than at logarithmic phase (days 2 and 3).

FIGURE S2 | Mycobacterium bovis BCGwt and $M$. bovis BCG-Tn growth curve in the presence of dextrose (DEX) or cholesterol (CHOL) as carbon sources. (A) Optical density at $600 \mathrm{~nm}$; (B) Colony forming units.

FIGURE S3 | Morphological changes of BGC wt and BCG-Tn during exponential phase in the presence of different carbon sources.

Morphological changes in exponential phase of mycobacterial cultures after growth in the presence of dextrose (A-C) and (G-I) or colesterol (D-F) and (J-L) as carbon sources. BCGwt (A-F) or BCG-Tn (G-L) cells were harvested from the corresponding culture and stained by Ziehl-Neelsen $\mathbf{( A , D , G , J ) ~ o r ~ w i t h ~ A u r a m i n e ~}$ $\mathbf{( B , E , H , K )}$ or Red Nile $\mathbf{( C , F , I , L ) ~ t h e ~ t w o ~ l a s t ~ b y ~ f l u o r e s c e n t ~ m i c r o s c o p y . ~}$

FIGURE S4 | Levels of expression of genes in M. bovis BCGwt and $M$. bovis BCG-Tn normalized with 16S rRNA. Levels of expression in the presence of dextrose (DEX) or cholesterol (CHOL) during exponential (EXP) and stationary (ST) phases of growth. Mean values of at least three amplifications per target and corresponding error bars are indicated.

FIGURE S5 | Levels of expression of ncRNAs in M. bovis BCGwt and M. bovis BCG-Tn normalized with 16S rRNA. Levels of expression in the presence of dextrose (DEX) or cholesterol (CHOL) during exponential (EXP) and stationary (ST) phases of growth. Mean values of at least three amplifications per target and corresponding error bars are indicated.

delivery to Mycobacterium tuberculosis. Proc. Natl. Acad. Sci. U.S.A. 94, 10961-10966. doi: 10.1073/pnas.94.20.10961

Barker, L. P., Brooks, D. M., and Small, P. L. (1998). The identification of Mycobacterium marinum genes differentially expressed in macrophage phagosomes using promoter fusions to green fluorescent protein. Mol. Microbiol. 29, 1167-1177. doi: 10.1046/j.1365-2958.1998.00996.x

Brosch, R., Gordon, S. V., Marmiesse, M., Brodin, P., Buchrieser, C., Eiglmeier, K., et al. (2002). A new evolutionary scenario for the Mycobacterium tuberculosis complex. Proc. Natl. Acad. Sci. U.S.A. 99, 3684-3689. doi: 10.1073/pnas. 052548299

Camacho, L. R., Ensergueix, D., Perez, E., Gicquel, B., and Guilhot, C. (1999). Identification of a virulence gene cluster of Mycobacterium tuberculosis by signature-tagged transposon mutagenesis. Mol. Microbiol. 34, 257-267. doi: 10.1046/j.1365-2958.1999.01593.x

Casabon, I., Zhu, S. H., Otani, H., Liu, J., Mohn, W. W., and Eltis, L. D. (2013). Regulation of the KstR2 regulon of Mycobacterium tuberculosis by a cholesterol catabolite. Mol. Microbiol. 89, 1201-1212. doi: 10.1111/mmi. 12340 
Chalfie, M., Tu, Y., Euskirchen, G., Ward, W. W., and Prasher, D. C. (1994). Green fluorescent protein as a marker for gene expression. Science 263, 802-805. doi: 10.1126/science.8303295

Chang, J. C., Miner, M. D., Pandey, A. K., Gill, W. P., Harik, N. S., Sassetti, C. M., et al. (2009). igr Genes and Mycobacterium tuberculosis cholesterol metabolism. J. Bacteriol. 191, 5232-5239. doi: 10.1128/JB.00452-09

Cirillo, J. D., Barletta, R. G., Bloom, B. R., and Jacobs, W. R. Jr. (1991). A novel transposon trap for mycobacteria: isolation and characterization of IS1096. J. Bacteriol. 173, 7772-7780. doi: 10.1128/jb.173.24.7772-7780.1991

Cody, C. W., Prasher, D. C., Westler, W. M., Prendergast, F. G., and Ward, W. W. (1993). Chemical structure of the hexapeptide chromophore of the Aequorea green-fluorescent protein. Biochemistry 32, 1212-1218. doi: 10.1021/ bi00056a003

Cole, S. T., Brosch, R., Parkhill, J., Garnier, T., Churcher, C., Harris, D., et al. (1998). Deciphering the biology of Mycobacterium tuberculosis from the complete genome sequence. Nature 393, 537-544. doi: 10.1038/31159

Cormack, B. P., Valdivia, R. H., and Falkow, S. (1996). FACS-optimized mutants of the green fluorescent protein (GFP). Gene 173, 33-38. doi: 10.1016/03781119(95)00685-0

Cox, J. S., Chen, B., Mcneil, M., and Jacobs, W. R. Jr. (1999). Complex lipid determines tissue-specific replication of Mycobacterium tuberculosis in mice. Nature 402, 79-83.

Cubero, N., Esteban, J., Palenque, E., Rosell, A., and Garcia, M. J. (2013). Evaluation of the detection of Mycobacterium tuberculosis with metabolic activity in culture-negative human clinical samples. Clin. Microbiol. Infect. 19, 273-278. doi: 10.1111/j.1469-0691.2012.03779.x

Cubitt, A. B., Heim, R., Adams, S. R., Boyd, A. E., Gross, L. A., and Tsien, R. Y. (1995). Understanding, improving and using green fluorescent proteins. Trends Biochem. Sci. 20, 448-455. doi: 10.1016/S0968-0004(00)89099-4

Dandie, C. E., Bentham, R. H., and Thomas, S. M. (2006). Use of reporter transposons for tagging and detection of Mycobacterium sp. strain 1B in PAHcontaminated soil. Appl. Microbiol. Biotechnol. 71, 59-66. doi: 10.1007/s00253005-0121-8

Deb, C., Lee, C. M., Dubey, V. S., Daniel, J., Abomoelak, B., Sirakova, T. D., et al. (2009). A novel in vitro multiple-stress dormancy model for Mycobacterium tuberculosis generates a lipid-loaded, drug-tolerant, dormant pathogen. PLoS ONE 4:e6077. doi: 10.1371/journal.pone.0006077

Dokladda, K., Billamas, P., and Palittapongarnpim, P. (2015). Different behaviours of promoters in Mycobacterium tuberculosis H37Rv and H37Ra. World J. Microbiol. Biotechnol. 31, 407-413. doi: 10.1007/s11274-014-1794-x

Forrellad, M. A., Klepp, L. I., Gioffre, A., Sabio, J., Morbidoni, H., De La Paz Santangelo, M., et al. (2013). Virulence factors of the Mycobacterium tuberculosis complex. Virulence 4, 3-66. doi: 10.4161/viru.22329

Francklyn, C. S., and Minajigi, A. (2010). tRNA as an active chemical scaffold for diverse chemical transformations. FEBS Lett. 584, 366-375. doi: 10.1016/j. febslet.2009.11.045

Garcia, M. J., and Lopez, M. R. (2016). Editorial commentary: Do we have strategies to improve the preventive treatment of latent tuberculosis infection? Clin. Infect. Dis. 62, 1401-1402. doi: 10.1093/cid/ciw132

Gonzalez-y-Merchand, J. A., Garcia, M. J., Gonzalez-Rico, S., Colston, M. J., and Cox, R. A. (1997). Strategies used by pathogenic and nonpathogenic mycobacteria to synthesize rRNA. J. Bacteriol. 179, 6949-6958. doi: 10.1128/ jb.179.22.6949-6958.1997

Griffin, J. E., Gawronski, J. D., Dejesus, M. A., Ioerger, T. R., Akerley, B. J., and Sassetti, C. M. (2011). High-resolution phenotypic profiling defines genes essential for mycobacterial growth and cholesterol catabolism. PLoS Pathog. 7:e1002251. doi: 10.1371/journal.ppat.1002251

Griffin, J. E., Pandey, A. K., Gilmore, S. A., Mizrahi, V., Mckinney, J. D., Bertozzi, C. R., et al. (2012). Cholesterol catabolism by Mycobacterium tuberculosis requires transcriptional and metabolic adaptations. Chem. Biol. 19, 218-227. doi: 10.1016/j.chembiol.2011.12.016

Gunther, G. (2014). Multidrug-resistant and extensively drug-resistant tuberculosis: a review of current concepts and future challenges. Clin. Med. 14, 279-285. doi: 10.7861/clinmedicine.14-3-279

Harris, N. B., Feng, Z., Liu, X., Cirillo, S. L., Cirillo, J. D., and Barletta, R. G. (1999). Development of a transposon mutagenesis system for Mycobacterium avium subsp. paratuberculosis. FEMS Microbiol. Lett. 175, 21-26. doi: 10.1111/j.15746968.1999.tb13597.x
Herrmann, B., Stolt, P., Abdeldaim, G., Rubin, C. J., Kirsebom, L. A., and Thollesson, M. (2014). Differentiation and phylogenetic relationships in Mycobacterium spp with special reference to the RNase P RNA gene rnpB. Curr. Microbiol. 69, 634-639. doi: 10.1007/s00284-014-0630-8

Klepp, L. I., Forrellad, M. A., Osella, A. V., Blanco, F. C., Stella, E. J., Bianco, M. V., et al. (2012). Impact of the deletion of the six mce operons in Mycobacterium smegmatis. Microbes Infect. 14, 590-599. doi: 10.1016/j.micinf.2012. 01.007

Kwon, Y. M., Ricke, S. C., and Mandal, R. K. (2016). Transposon sequencing: methods and expanding applications. Appl. Microbiol. Biotechnol. 100, 31-43. doi: 10.1007/s00253-015-7037-8

Lin, T., Troy, E. B., Hu, L. T., Gao, L., and Norris, S. J. (2014). Transposon mutagenesis as an approach to improved understanding of Borrelia pathogenesis and biology. Front. Cell Infect. Microbiol. 4:63. doi: 10.3389/fcimb. 2014.00063

Machowski, E. E., Mcadam, R. A., Derbyshire, K. M., and Mizrahi, V. (2000). Construction and application of mycobacterial reporter transposons. Gene 253, 67-75. doi: 10.1016/S0378-1119(00)00238-9

Martin, C., Timm, J., Rauzier, J., Gomez-Lus, R., Davies, J., and Gicquel, B. (1990). Transposition of an antibiotic resistance element in mycobacteria. Nature 345, 739-743. doi: 10.1038/345739a0

Mcadam, R. A., Quan, S., and Guillot, C. (2000). "Mycobacterial transposons and their applications," in Molecular Genetic of Mycobacteria, eds G. F. Hatfull and W. R. Jacobs (Washington DC: ASM Press), 69-84.

Mcadam, R. A., Weisbrod, T. R., Martin, J., Scuderi, J. D., Brown, A. M., Cirillo, J. D., et al. (1995). In vivo growth characteristics of leucine and methionine auxotrophic mutants of Mycobacterium bovis BCG generated by transposon mutagenesis. Infect.Immun. 63, 1004-1012.

Mendiola, M. V., Martin, C., Otal, I., and Gicquel, B. (1992). Analysis of the regions responsible for IS6110 RFLP in a single Mycobacterium tuberculosis strain. Res. Microbiol. 143, 767-772. doi: 10.1016/0923-2508(92)90104-V

Miner, M. D., Chang, J. C., Pandey, A. K., Sassetti, C. M., and Sherman, D. R. (2009). Role of cholesterol in Mycobacterium tuberculosis infection. Indian J. Exp. Biol. 47, 407-411.

Munshi, T., Gupta, A., Evangelopoulos, D., Guzman, J. D., Gibbons, S., Keep, N. H., et al. (2013). Characterisation of ATP-dependent mur ligases involved in the biogenesis of cell wall peptidoglycan in Mycobacterium tuberculosis. PLoS ONE 8:e60143. doi: 10.1371/journal.pone.0060143

Nesbitt, N. M., Yang, X., Fontan, P., Kolesnikova, I., Smith, I., Sampson, N. S., et al. (2010). A thiolase of Mycobacterium tuberculosis is required for virulence and production of androstenedione and androstadienedione from cholesterol. Infect. Immun. 78, 275-282. doi: 10.1128/IAI.00893-09

Otal, I., Gomez, A. B., Kremer, K., De Haas, P., Garcia, M. J., Martin, C., et al. (2008). Mapping of IS6110 insertion sites in Mycobacterium bovis isolates in relation to adaptation from the animal to human host. Vet. Microbiol. 129, 333-341. doi: 10.1016/j.vetmic.2007.11.038

Ouellet, H., Johnston, J. B., and De Montellano, P. R. (2011). Cholesterol catabolism as a therapeutic target in Mycobacterium tuberculosis. Trends Microbiol. 19, 530-539. doi: 10.1016/j.tim.2011.07.009

Pandey, A. K., and Sassetti, C. M. (2008). Mycobacterial persistence requires the utilization of host cholesterol. Proc. Natl. Acad. Sci. U.S.A. 105, 4376-4380. doi: 10.1073/pnas.0711159105

Parish, T., and Stoker, N. G. (eds). (1998). "Electroporation of Mycobacteria," in Mycobacteria Protocols (Methods in Molecular Biology), (Totowa, NJ: Humana Press), 129-144.

Pelicic, V., Jackson, M., Reyrat, J. M., Jacobs, W. R. Jr., Gicquel, B., and Guilhot, C. (1997). Efficient allelic exchange and transposon mutagenesis in Mycobacterium tuberculosis. Proc. Natl. Acad. Sci. U.S.A. 94, 10955-10960. doi: 10.1073/pnas.94. 20.10955

Prasher, D. C., Eckenrode, V. K., Ward, W. W., Prendergast, F. G., and Cormier, M. J. (1992). Primary structure of the Aequorea victoria green-fluorescent protein. Gene 111, 229-233. doi: 10.1016/0378-1119(92)90691-H

Prod'hom, G., Lagier, B., Pelicic, V., Hance, A. J., Gicquel, B., and Guilhot, C. (1998). A reliable amplification technique for the characterization of genomic DNA sequences flanking insertion sequences. FEMS Microbiol. Lett. 158, 75-81. doi: 10.1111/j.1574-6968.1998.tb12803.x

Ramos, J. L., Martinez-Bueno, M., Molina-Henares, A. J., Teran, W., Watanabe, K., Zhang, X., et al. (2005). The TetR family of transcriptional repressors. 
Microbiol. Mol. Biol. Rev. 69, 326-356. doi: 10.1128/MMBR.69.2.326-356. 2005

Rengarajan, J., Bloom, B. R., and Rubin, E. J. (2005). Genome-wide requirements for Mycobacterium tuberculosis adaptation and survival in macrophages. Proc. Natl. Acad. Sci. U.S.A. 102, 8327-8332. doi: 10.1073/pnas.05032 72102

Rodriguez, J. G., Hernandez, A. C., Helguera-Repetto, C., Aguilar Ayala, D., Guadarrama-Medina, R., Anzola, J. M., et al. (2014). Global adaptation to a lipid environment triggers the dormancy-related phenotype of Mycobacterium tuberculosis. MBio 5:e1125-14. doi: 10.1128/mBio.01125-14

Rohde, K. H., Veiga, D. F., Caldwell, S., Balazsi, G., and Russell, D. G. (2012). Linking the transcriptional profiles and the physiological states of Mycobacterium tuberculosis during an extended intracellular infection. PLoS Pathog. 8:e1002769. doi: 10.1371/journal.ppat.1002769

Sambrook, J., Fritsch, E. F., and Maniatis, T. (1989). Molecular Cloning, a Laboratory Manual. Cold Spring Harbor, NY: Cold Spring Harbor Laboratory Press.

Schnappinger, D., Ehrt, S., Voskuil, M. I., Liu, Y., Mangan, J. A., Monahan, I. M., et al. (2003). Transcriptional adaptation of Mycobacterium tuberculosis within macrophages: insights into the phagosomal environment. J. Exp. Med. 198, 693-704. doi: 10.1084/jem.20030846

Triccas, J. A., Berthet, F. X., Pelicic, V., and Gicquel, B. (1999). Use of fluorescence induction and sucrose counterselection to identify Mycobacterium tuberculosis genes expressed within host cells. Microbiology 145(Pt 10), 2923-2930. doi: 10.1099/00221287-145-10-2923
Valdivia, R. H., and Falkow, S. (1998). Flow cytometry and bacterial pathogenesis. Curr. Opin. Microbiol. 1, 359-363. doi: 10.1016/S1369-5274(98) 80042-8

Wang, S., and Hazelrigg, T. (1994). Implications for bcd mRNA localization from spatial distribution of exu protein in Drosophila oogenesis. Nature 369, 400-403. doi: 10.1038/369400a0

Wipperman, M. F., Sampson, N. S., and Thomas, S. T. (2014). Pathogen roid rage: cholesterol utilization by Mycobacterium tuberculosis. Crit. Rev. Biochem. Mol. Biol. 49, 269-293. doi: 10.3109/10409238.2014.895700

Conflict of Interest Statement: The authors declare that the research was conducted in the absence of any commercial or financial relationships that could be construed as a potential conflict of interest.

The reviewer JM and handling Editor declared their shared affiliation and the handling Editor states that the process nevertheless met the standards of a fair and objective review.

Copyright (C) 2017 Otal, Pérez-Herrán, Garcia-Morales, Menéndez, Gonzalez-yMerchand, Martín and García. This is an open-access article distributed under the terms of the Creative Commons Attribution License (CC BY). The use, distribution or reproduction in other forums is permitted, provided the original author (s) or licensor are credited and that the original publication in this journal is cited, in accordance with accepted academic practice. No use, distribution or reproduction is permitted which does not comply with these terms. 